\title{
Improvement of the mathematical model of the diagram of deformation of the compressed composite steel and concrete structures
}

\author{
Stanislav Fomin ${ }^{1 *}$, Yuriy Izbash $^{1}$, Iryna Plakhotnikova ${ }^{1}$, Serhii Butenko ${ }^{1}$, and Ruslan \\ Shemet ${ }^{1}$ \\ ${ }^{1}$ Department of reinforced concrete and stone structures, Kharkiv National University of Civil \\ Engineering and Architecture, 61002, Kharkiv, 40, Sumskaya Str., Ukraine
}

\begin{abstract}
The mathematical model of the stress-strain ratio of compressed concrete at elevated temperatures for composite structures described in Eurocode EN 1994-1-2:2005 Eurocode 4 divided in two stages: Stage 1 - represents the ascending branch and is defined by two parameters: compressive strength $\mathrm{f}_{\mathrm{c}, \theta}$ and corresponding deformations $\varepsilon_{\mathrm{cu}, \theta}$, stage II - the descending branch which is accepted for numerical methods. The design practice showed deficiencies in the provisions on models of deformation diagrams given in Eurocode 2. Part 1-2 General provisions. Structural Fire Design. (EN 1992-1-2:2004), (ENV 1992-1-2:1995), which were reflected in the national standards in the process of harmonization. A technique for determining the refined diagrams $" \sigma_{c, \theta}-\varepsilon_{c, \theta}$ " was developed for the design of composite reinforced concrete structures in case of fire. Diagram parameter values were adjusted for concretes based on silicate filler at high temperatures, the mathematical stress-strain model of the concrete under compression and high temperatures was specified.
\end{abstract}

\section{Introduction}

The order of Ministry of Regional Development of Ukraine with the participation of GP GNIISK KNUCEA has developed national standard DBN V.2.6 - 160:2010 for the design of composite steel and concrete structures [1], and standard DSTU-N-P B B.2.6 - 159:2010 [2] on structural fire design by now. The design practice has shown the shortcomings of the provisions on the deformation diagram models given in Eurocode 2. Part 1-2: General rules - Structural fire design (EN 1992-1-2:2004 [3]), (ENV 1992-1-2:1995 [4]), which were reflected in national standards [5] in the course of harmonization.

\section{Analysis of recent studies}

In this study [6], we developed a method for determination of $\varepsilon_{c u l, \theta}$ criterion of carrying capacity of concrete to calculate the fire resistance of concrete structures of buildings, based on which the data on strength and deformation properties of concrete at higher

\footnotetext{
${ }^{*}$ Corresponding author: sfomin $@$ ukr.net
} 
temperatures given in Eurocode EN 1992-1-2:2004 and ENV 1992-1-2:1995 were clarified. The comparison of a diagram according to DBN V.2.6 - 98 [7] at normal temperature with a similar diagram of the standard [2] shows a significant overestimation of the value $\varepsilon_{c u l, \theta=20^{\circ}}=0.0200=20 \%$ (based on [7] $\varepsilon_{c u l, c k}=2.4$ to $4.5 \%$, depending on the concrete class). These diagrams were obtained on special presses provided with heating device and servocontrol of pressure in the press cylinder, which allows to pass along the descending branch practically to zero voltage. In this case, the descending branch is no longer an area of deformation of whole concrete specimen, but the area of deformation of individual parts of crushed concrete. So, the values of deformations in columns 4 and 7 of Table 3.1 [2] are not maximum concrete deformation $\varepsilon_{c u l, \theta}$.

DSTU-N-P B V.2.6-159:2010 (EN 1994-1-2:2005, MOD) [2] harmonized with EN 1994-1-2:2005 [4] strengthened erroneous concept of Eurocodes specified, which proposed linear approximation of descending branches of the concrete deformation diagram with silica filler under high temperatures.

The paper purpose is to improve the mathematical stress-strain model of concrete under compression and high temperatures. The specification of the criteria of the carrying capacity of concrete in the calculation of the fire resistance of composite structures in EN 1994-1-2:2005.

\section{The results of the theoretical studies performed}

In section 3, of the standard [2], we indicated that the strength of concrete and the mechanical properties at high temperatures can be determined from the stress-strain dependences given in EN 1992-1-2 [5], and as shown in Fig. 3.2 [2]. The stress-strain dependencies on the ascending branch shall be determined by two parameters: strength for compression $f_{c, \theta}$ and deformation $\varepsilon_{c u, \theta}$, which corresponds to $f_{c, \theta}$.

$$
\sigma_{c, \theta}=f_{c, \theta}\left\{3\left(\frac{\varepsilon_{c, \theta}}{\varepsilon_{c u, \theta}}\right) /\left[2+\left(\frac{\varepsilon_{c, \theta}}{\varepsilon_{c u, \theta}}\right)^{3}\right]\right\}
$$

Using formula (1), we would obtain data on the elasticity modulus $E_{c \kappa, \theta}$ during heating that are absent in the standard, but it is complemented by Table 3.1 [4] of the values of the diagram parameters. In this table, the deformations $\varepsilon_{c l, \theta}$ are taken the same for all classes of concrete, including for silicate (column 4) and carbonate (column 7) fillers. Therefore, depending on the concrete class in the formula (1), we can vary only the value of the compression strength $f_{c}$, so these diagrams, even on the ascending branch, incorrectly reflect the actual physical properties of non-linearity.

In DBN [7] (at $20^{\circ} \mathrm{C}$ ) it was proposed to use two equations for describing the relationship between $\sigma_{c}$ and $\varepsilon_{c}$ for short-term axial load. The equation (2) that is used in EN 1992-1-1:2005 [8]:

$$
\frac{\sigma_{n}}{f_{c k}}=\frac{k \eta-\eta^{2}}{1+(k-2) \eta}
$$

where:

$$
\eta=\varepsilon_{c} / \varepsilon_{c 1, c k} k=1.05 E_{c k} \varepsilon_{c 1, c k} / f_{c k, p r i s m}
$$


and equation (4) in the form of a polynomial of the fifth degree, which is based on the results of numerous experimental studies of NIISK, the statistical processing of which allowed us to offer a more complete regulatory framework.

$$
\sigma_{\tilde{n}}=f_{(c k),(c d)} \sum_{k=1}^{5} a_{k} \eta^{k}
$$

The limits of use were determined for both formulas:

$$
0<\left|\varepsilon_{c}\right|<\left|\varepsilon_{c u 1, c k}\right|
$$

where $\varepsilon_{c u l, c \kappa}$ - nominal maximum concrete deformations.

Fig. 1 shows complete diagrams " $\sigma_{c}-\varepsilon_{c}$ " at $20^{\circ} \mathrm{C}$ for concrete class $\mathrm{C} 16 / 20$ according to the formula (4) of DBN [7], formula (2) of Eurocode 2 [8] and the ascending branch according to the formula (1) DSTU, EN 1992 [4]. As we can see from this figure, the diagrams according to DBN and EN 1992-1-1 on the ascending branch practically coincide, the diagram according to the formula (1) of DSTU [2] has significant deviation - the curve according to DSTU is flatter. This arises due to large values $\varepsilon_{c l, c k, \theta}=2.5 \%$ o $(0.0025)$ compared to the baseline.

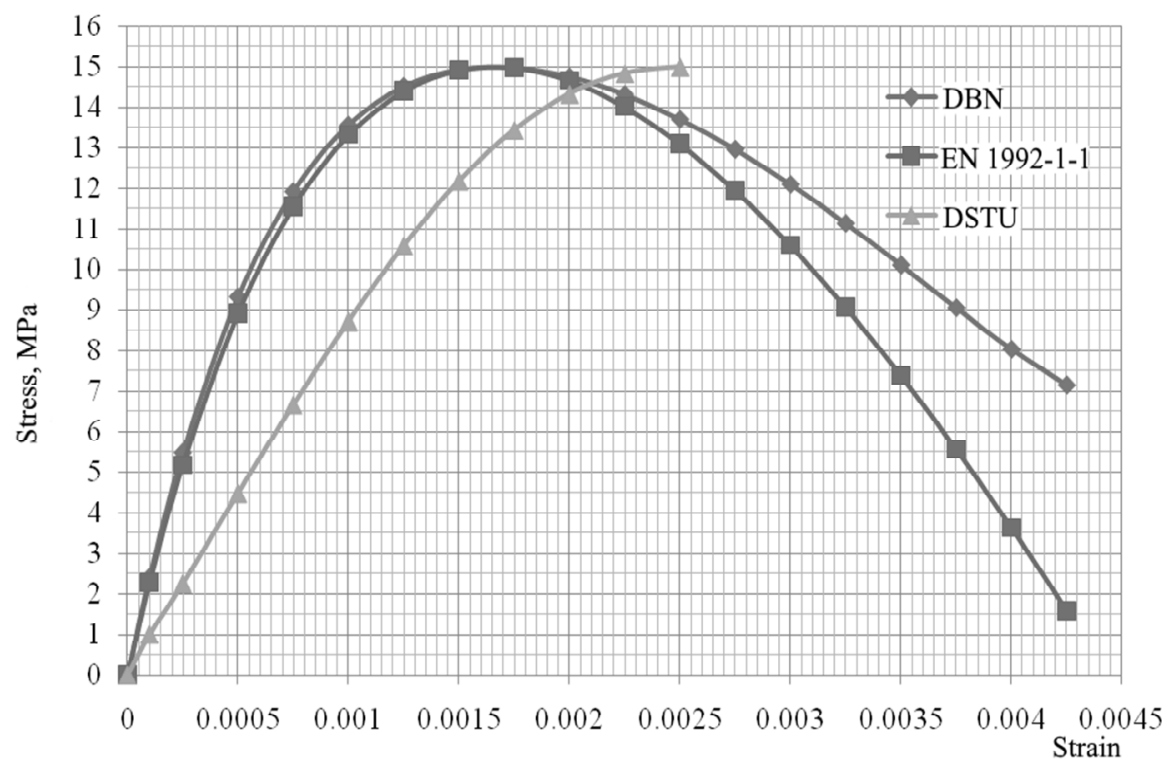

Fig.1. Comparison of diagrams " $\sigma_{c}-\varepsilon_{c}$ " according to the formula (2) of DBN, formula (4) and formula (1) of DSTU [4] for concrete class C $16 / 20$ at $\theta=20^{\circ} \mathrm{C}$.

If using this curve, we will calculate the value of the elasticity modulus, we will obtain a value $E_{c k}=0.4 \cdot 15 / 0.00065=9.23 \mathrm{GPa}$, which is 2.5 times lower than the standard $E_{c k}=23 \mathrm{GPa}$. Therefore, the formula (1) of Eurocode [2] is unsuitable for determination of modulus of elasticity.

The replacement of deformation $\varepsilon_{c l, \theta}$ with $\varepsilon_{c u, \theta}$, and deformations $\varepsilon_{c u l, \theta}$ - with $\varepsilon_{c e, \theta}$ (maximum deformations during fire on fig. 3.2 [2] is uncomprehended. 


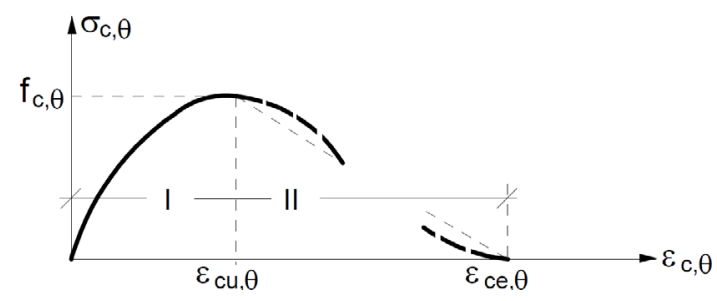

Fig.2. Mathematical model [2].

In addition, stress-strain relations for concrete of silicate filler under high temperature were proposed in Appendix V. At the linearly descending section (shown in Figure V.1 of the appendix), the maximum deformation $\varepsilon_{c e, \theta}=47.5 \%$. They correspond to the mathematical formulation shown in Fig. 3, and the data in Table 1 [2]. The allowable range and the recommended values of the deformation $\varepsilon_{c u, \theta}$ for $f_{c, \theta}$ (Fig. 1) is proposed to determine from the Table 2 (V.1 [2]). Table 2 does not differ from Table 3.1 EN 1992-1-2 [5] for ordinary concrete based on silicate filler except for that deformations $\varepsilon_{c l, \theta}$ (second column) in is were replaced with deformations $\varepsilon_{c u, \theta}$, and deformations $\varepsilon_{c u l, \theta}$ - with deformations $\varepsilon_{c u l, \theta}-$ (third column).

To perform elastic and non-elastic calculations of the fire resistance in program complexes, the values of the elasticity moduli of the compressed $E_{t c, \theta}$ and extended $E_{t c, \theta}$ concrete, deformations $\varepsilon_{c l, \theta}$ and $\varepsilon_{t c l, \theta}$, relevant compression $f_{c, \theta}$ and tensile strengths $f_{t c, \theta}$, limit deformations $\varepsilon_{c u, \theta}, \varepsilon_{t c u, \theta}$ and limit stresses relevant to them $\sigma_{c u, \theta}$ and $\sigma_{t c u, \theta}$ are needed.

Actual limit deformations $\varepsilon_{c u l, \theta}$ determined based on the energy approach and are shown in adjusted Table of the paper [6]. In the paper [9], we developed a method for determination the heave concrete elasticity modulus under high temperature heating, criterion of carrying capacity of concrete $\varepsilon_{c u l, \theta}$ to calculate the fire resistance of concrete structures of buildings, based on which the data on strength and deformation properties of concrete at higher temperatures given in EN 1992-1-2:2004 and ENV 1994-1-2:2005.

The significant issues arose in the considered model on the ascending branch. One is that the concrete classes are not fully taken into account on the diagrams. With concrete class, the value of strength $f_{c m}$ only increases, and deformation $\varepsilon_{c l}$ remain the same and equal $\varepsilon_{c l}=2.5 \%$. This, as evidenced by Fig. 2, leads to large errors in the determination of the elastic modulus of concrete and "stress-strain" dependence is incorrectly described. Another is that such a stress-strain dependence is unused, which not properly represents the nature of work of concrete considered. Diagrams " $\sigma_{c}-\varepsilon_{c}$ " of concrete in the basic normative documents take into account the necessary reference points: in the formula (2) of the Eurocode 2 [8] the coefficient $k=1.05 E_{c k} \varepsilon_{c l, c k} / f_{c m}$ is introduced, in the formula (3) of DBN [7] the polynomial coefficient are selected based on the conditions [9]:

- the curve passes through the origin;

- $\quad$ the secant modulus at stresses $\sigma_{c}=0.3 f_{c k}$ is equal to the elesticity modulus $E_{c k}$, included into current norms;

- at deformations $\varepsilon_{c}=\varepsilon_{c l, c k}$ the stresses in the concrete reach maximum values and are equal to the prism strength $\sigma_{c}=f_{c k \text { prism; }}$;

- $\quad$ in the entire range of the curve existence $\varepsilon_{c}=0$ to $\varepsilon_{c u l}$ it has a single extremum at $\varepsilon_{c}=\varepsilon_{c l, c k}$.

When deriving the formula (1) [DSTU], the reference points described were not taken into account.

The processing of the stress-strain diagram of the compressed concrete under high temperatures provided in ENV 1992-1-2:1995 and using affinity effect between the diagrams in the cold (at $20^{\circ} \mathrm{C}$ ) and diagrams at heating [10] allows us to calculate " $\sigma_{c}-\varepsilon_{c}$ " 
diagrams of the predetermined class concrete based silicate filler at high temperatures by any formula built on the above assumptions.

For example, let us construct full diagrams for compressive concrete class C 16/20 according to the formula (2) of Eurocode 2 [8]. We will take data from Table 3.1 of EN 1992-1-1:2005 [8] for $\theta=20^{\circ} \mathrm{C}: f_{c m}=24 \mathrm{MPa}, E_{c m}=29.000 \mathrm{MPa}, \varepsilon_{c l, c k}=0.0019$, $\varepsilon_{c u l, c k}=0.0035$.

Then, the stress-strain dependence (2) will look like:

$$
\sigma_{c, \theta}=f_{c m, \theta} \frac{k \eta-\eta^{2}}{1+(k-2) \eta}
$$

where:

$$
\eta=\varepsilon_{c} / k_{\theta}=1.05 E_{c m} \varepsilon_{c 1, \theta} / f_{c m, \theta}
$$

This expression is fair at $0<\left|\varepsilon_{c}\right|<\left|\varepsilon_{c u l}, \theta\right|$, where $\varepsilon_{c u l, \theta}$ - nominal limit deformations at temperature.

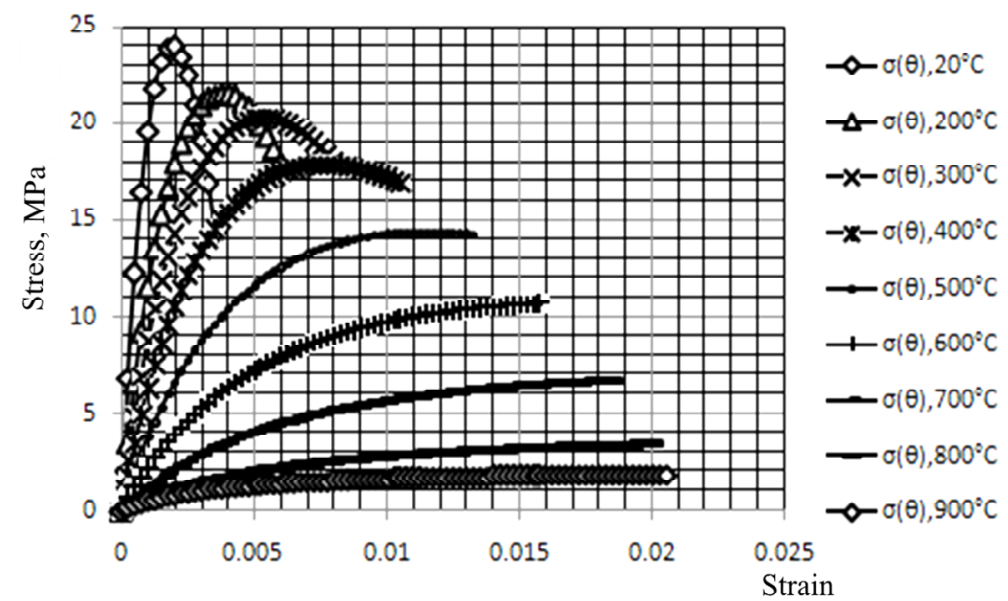

Fig. 3. Diagram " $\sigma_{c}-\varepsilon_{c}$ ” for concrete class C $16 / 20$ at elevated temperature.

\section{Conclusions}

The defects of strength and deformation properties of concrete at higher temperature given in EN 1994-1-2:2005 Eurocode were found, which were reflected in the national standard DSTU-N-P B V.2.6-159:2010 in the course of harmonization. A methodology was developed for determining revised " $\sigma_{c, \theta}-\varepsilon_{c, \theta}$ " charts for the design of composite steel and concrete structures during a fire. Diagram parameter values were adjusted for concretes based on silicate filler at high temperatures, the mathematical stress-strain model of the concrete under compression and high temperatures was specified.

\section{References}

1. DBN V.2.6-160:2010 Composite steel and concrete structures. Basic provisions. Minregionbud of Ukraine, Kiev (2011) 
2. DSTU-N-P B V.2.6-159:2010 Structures of buildings and facilities. Design of composite steel and concrete structures. Part 1-2. General provisions. Structural fire design. (EN 1994-1-2:2005, Eurocode 4. MOD), Kiev (2010)

3. EN 1992-1-2: 2004 Eurocode 2: Design of concrete structures - Part 1-2: General rules - Structural fire design, Brussels (2004)

4. ENV 1992-1-2:1995 Eurocode 2: Design of Concrete Structures - Part 1-2: General Rules - Structural Fire Design, Brussels (1995)

5. DSTU-N B EN 1992-1-2:2012. Eurocode 2: Design of concrete structures. Part 1-2: General rules. Structural fire design. (EN 1992-1-2:2004, IDT). Minregionbud of Ukraine, Kiev (2012)

6. S.L. Fomin, A.I. Davidenko, V.G. Poklonsky, News of Odessa State Academy of construction and architecture, Odessa, (2012)

7. DBN V.2.6-98:2009 Structures of buildings and facilities. Concrete and reinforced concrete structures. Basic provisions. Ministry of regional development and construction of Ukraine, Kiev (2011)

8. EN 1992-1-1:2005 Eurocode 2: Design of reinforced concrete structures - Part 1-1: General norms and rules for structures, Brussels (2005)

9. S.L. Fomin, Sh. Kasem, V.G. Poklonskiy, Science bulletin of construction, 73, 427 (2013)

10. A.N. Bambura, Materials of the First Ukrainian scientific - technical conference, Scientific - practical problems of modern concrete, Kiev, (1996) 